\title{
EL “CIUDADANO” AMAZÓNICO EN EL DISCURSO POLÍTICO OFICIAL
}

\author{
Marco Antonio Lovón Cueva \\ Universidad Peruana de Ciencias Aplicadas (UPC) \\ mlovon@upc.edu.pe
}

Recibido: 05/02/2018 - Aceptado: 21/09/2018

doi.org/10.17533/udea.lyl.n75a02

\begin{abstract}
Resumen: La explotación de la Amazonía se sostiene bajo los discursos de la civilización y colonización. Para ello, el aparato ideológico racista construye una imagen negativa de los aborígenes amazónicos. En este artículo, se estudia el discurso del expresidente Alan García como ejemplo de los discursos políticos antiamazónicos. Se demuestra que su discurso está basado en dos creencias discriminatorias: 1) Entre dos clases de ciudadanos, los amazónicos son ciudadanos de segunda clase y 2) El crecimiento económico es obstaculizado por grupos primitivos como los amazónicos. Para ello, desde el análisis crítico del discurso, se examinan las estrategias léxicas y discursivas presentes en un texto del citado mandatario. Finalmente, se concluye que el discurso de Alan García es una manifestación de una práctica social que reproduce discriminación en el país.
\end{abstract}

Palabras clave: Amazonía; discurso; práctica social; extractivismo; ciudadano.

\section{THE AMAZONIAN "CITIZEN" IN THE OFFICIAL POLITICAL DISCOURSE}

\begin{abstract}
The exploitation of the Amazon is based on civilization and colonization discourses. For this, the racist ideological apparatus constructs a negative image of the Amazonian aborigines. In this paper, the speech of the former President Alan García is studied as an example of antiamazonic political discourses. It showed that his discourse is related to two discriminatory beliefs: 1) Between two classes of citizens, the Amazonians are second-class citizens, and 2) Economic growth is hindered by primitive groups such as the Amazonian. Therefore, from the Critical Discourse Analysis, the lexical and discursive strategies are examined. Finally, it is concluded that his speech is a manifestation of a social practice that reproduces discrimination in the country.
\end{abstract}

Keywords: Amazon; Discourse; Social Practice; Extractivism; Citizen. 


\section{Introducción}

Tos discursos antiamazónicos se construyen a partir del uso de ciertas estrategias Lléxicas y discursivas que representan negativamente a los pobladores amazónicos, a sus comunidades, a sus costumbres y a sus lenguas, los cuales finalmente terminan por cuestionar su existencia. Estos discursos de rechazo se usan para asociarlos con rasgos de "primitivo", "retraso" y "salvajismo", que la sociedad occidental elabora, hereda y acepta, puesto que perciben a los pobladores amazónicos como incivilizados e inferiores, y que incluso pueden convencer a los mismos amazónicos de que ellos constituyen el problema.

Según Trujillo (2001: p. 12), con los conquistadores españoles, la Amazonía se percibió como un espacio en donde cohabitaban la naturaleza y las amazonas, es decir, las mujeres guerreras de una belleza extraordinaria, junto con «seres medio salvajes, desnudos y caníbales que se presentaban reacios a todo contacto, evangelización y civilización». Con los conquistadores, el "paraíso verde" se construye como un espacio que contiene pobladores "salvajes" que hay que "domesticar". Las distintas formas negativas de pensar al poblador amazónico serán asimiladas a través del tiempo. Por ejemplo, actualmente, las élites mestizas de la provincia de Satipo, provincia peruana situada en la parte oriental del Departamento de Junín, discriminan a la población nativa con el fin de legitimar la invasión de territorios ancestrales del pueblo amazónico asháninka. Según Vigil (2010, p. 572), los colonos califican a los asháninka de "incivilizados", "no trabajadores", "irresponsables", "vulnerables", "académicamente ineficientes", "pobres", "desnutridos", "conformistas", "manipulables". Es decir, los colonos perpetúan la invasión pensando que los asháninka son "primitivos" y sus territorios se encuentran "vacíos". Para la misma autora, los discursos racistas expresan la discriminación hacia los nativos asháninka al caracterizarlos negativamente, incluso en el discurso paternalista o proteccionista que se expresa a través de la compasión (2010, p. 572). Formas de pensar al "otro" tales como las mencionadas han ingresado incluso en los textos escolares (Bisbe, 2009). En general, siguiendo a Pizarro (2009, p. 28), la Amazonia es una construcción discursiva elaborada por la lógica europea y occidental. Es una narración o resultado de varias narraciones.

En sí, los discursos antiamazónicos son discursos de la "otrificación”, los cuales naturalizan determinadas convenciones que producen, reproducen y sustentan relaciones de poder (van Dijk, 2009). La sociedad occidental, con su aparato estatal (Estado, constitución), sus fuerzas de coacción (policías y militares), su economía (mercado capitalista), y su educación y ciencia (formal y jerarquizante), ejerce control sobre los territorios amazónicos y sus habitantes. Dicho control se manifiesta 
en prácticas de colonización y de racialización (homogenización cultural, religiosa, lingüística), en el manejo de tierras y en el medioambiente en general (políticas de minería, petróleo, agua y tala). Evidentemente, los discursos antiamazónicos sostienen que estos pueblos y sus territorios son "salvajes" y necesitan ser "civilizados" (Arrunátegui, 2010b, p. 431), o son "ociosos" y requieren ser "utilizados". Así, por ejemplo, entre tales discursos, destaca el del mismo expresidente del Perú, Alan García, quien ha sostenido que "Hay millones de hectáreas para madera que están ociosas, otros millones de hectáreas que las comunidades y asociaciones no han cultivado ni cultivarán" (García, 2007). Discursos hegemónicos como este reproducen la creencia de que la tierra debe ser usada a favor del Estado y las empresas extractivas; en otras palabras, no debe ser desperdiciada. Por eso, se cree que los recursos naturales de la Amazonía necesariamente tienen que explotarse a pesar de que la explotación podría generar daños ambientales y socioambientales irreparables, los mismos que se minimizan bajo la idea de que los daños ocasionados en el ecosistema "agreste" son mínimos o nulos en comparación con el "desperdicio" de tierras por parte de los nativos. Para la sociedad occidental, el poblador amazónico constituye un impedimento para el desarrollo. De acuerdo con Mendes (1992, p. 22), «los pueblos indígenas han sido y son considerados como un obstáculo para el desarrollo, la conquista y la colonización de la Amazonía. La razón está en las tierras que ocupan desde tiempos remotos, en su forma de utilizar los recursos y en su cultura». Para los occidentales, los pueblos amazónicos no facilitan la implementación de proyectos empresariales de extracción ni la inversión privada o pública; por tanto, son vistos como grupos étnicos contrarios al crecimiento o desarrollo de todo un país. Los pobladores amazónicos son para los occidentales "incivilizados". El mismo Mendes (1992, p. 22) señala que los conquistadores, los misioneros, los caucheros, los colonos y los mineros ilegales buscaron y continúan buscando convertir a los indígenas «a la religión cristiana, civilizarlos o esclavizarlos, o quitarles sus tierras y recursos», porque «no producen para el desarrollo del país». De alguna manera, los occidentales hacen ver que sus habitantes como son "incultos", y hasta "egoístas", ignoran los problemas económicos del país, e incluso los daños ambientales que los afectan, por lo que deben ser educados y protegidos a través de la sociedad occidental, asumida como "racional" y "justa", de manera que ellos se convencerán de que los territorios de la selva deben ser empleados principalmente para fines empresariales y estatales que "garantizan" el desarrollo de un país. La idea de "incivilizados" se asocia, culturalmente, con prácticas de exclusión y desprecio que cala en el imaginario de las personas, en contra de prácticas de inclusión, participación y agencia de los pueblos amazónicos, quienes son, efectivamente, los principales promotores de su desarrollo espacial, temporal, lingüístico, histórico, ecológico de sus tierras. 
Dichas ideas y prácticas devienen con fuerza si son producidas y reproducidas por los políticos, por las instituciones políticas y las políticas públicas. Así, cobra fuerza el discurso del expresidente de la República del Perú, en el que se margina y establece una diferenciación entre los ciudadanos, en vez de lograr canalizar los medios de concertación y participación. Por ende, el discurso del expresidente Alan García es motivo de análisis del presente artículo, que busca evidenciar uno de los discursos racistas que asume a los amazónicos como "ciudadanos de segunda clase" bajo la creencia de que "se oponen al crecimiento económico" del país. Esta última creencia se sustenta, realmente, en la idea de que la economía de extracción de materias primas facilitará el desenvolvimiento y crecimiento económico que "goza" el país, por lo que se piensa que las personas que se oponen a este objetivo no buscan el progreso, sino el retroceso. Nuestro estudio se aboca al análisis discursivo, porque para nosotros el lenguaje es un instrumento de construcción de identidades, representaciones y relaciones, es el terreno donde tienen lugar las luchas de poder (Fairclough, 1989, p. 15).

\section{El discurso como práctica social: la representación de los otros}

La lucha por el uso de los espacios territoriales genera relaciones de poder que siguen vigentes desde la época colonial. El afán de conquista se sostiene en el discurso de despojar a los dominados de sus tierras por considerar que se encuentran al servicio de los dominantes. Este elemento ideológico construye una representación sobre los "subalternos" situados como inferiores. A la fecha, diferentes disciplinas académicas (Ciencias de la Salud, Ciencias de la Administración, Ingenierías, Derecho) no han dejado de propalar discursos de los "otros" como "desvalidos", "incivilizados", "enemigos", "intolerantes", "salvajes". Según Bhabha (1994), el discurso colonial, con el fin de justificar la conquista, ha construido al sujeto colonizado como "inferior"; por eso, el "otro" es visto como un ser "degenerado". El discurso colonial con base epistemológica busca imponer la lectura de los dominantes. El discurso colonial genera relaciones de supraordinación, conquista y desposesión de los recursos de los "otros". Se asimila un tipo de conocimiento que se hace familiar y aceptable frente a lo que se teme, se desconoce, se minoriza, se desaprueba, se reniega (Bhabha 1994, p. 98).

Según Fairclough (1992), los discursos no solo reflejan o representan entidades sociales y relaciones, sino que estos las construyen y las constituyen: moldean, anticipan, producen, otorgan sentido a la realidad. Los discursos que dirigen nuestras formas de pensar son aquellos con los que nos vemos expuestos. Seguimos discursos 
que van en la línea de nuestras creencias y que organizan el mundo en relación con ellas. Los discursos "son diferentes representaciones de la vida social cuya posición se halla intrínsecamente determinada; los actores sociales de distinta posición 'ven' y representan la vida social de maneras distintas, con discursos diferentes" (Fairclough, 1992, p. 182).

El discurso es, pues, entendido como práctica social constitutiva y generadora de realidades y relaciones sociales (Foucault, [(1969) 1990]): construye una representación de la realidad y funciona como una herramienta de difusión y establecimiento de ideologías y relaciones de poder. Es parte de la vida social y a la vez un instrumento que crea vida social. Todo mensaje es producido por una persona que pertenece a una institución o a un grupo social determinado y cada producción forma parte de las creencias de quienes conforman esos grupos. Los productos discursivos están cargados de creencias y subjetividades que tienen repercusiones en la sociedad en tanto que gozan de influencia directa sobre las formas de asumir la realidad y actuar en ella. De esta manera, los discursos se constituyen como prácticas sociales (Fairclough, 1992). El discurso como práctica social "construye, reproduce y transforma la realidad y, por tanto, es capaz de materializar ideologías, es decir, formas hegemónicas y naturalizadas de pensar que guían el actuar de las sociedades" (Arrunátegui, 2010a, p. 436). Así, cuando un presidente manifiesta un discurso o responde a una entrevista no puede mantenerse al margen de sus creencias y subjetividades, porque su voz es la voz de otros (van Dijk, 2010), y sus manifestaciones calan en el grupo de personas que lo escuchan y que consumen el tipo de discurso emitido. Cabe precisar que su discurso es también producto de discursos y creencias de los cuales se ha alimentado. En este sentido, el discurso es una actividad social que conduce a formas de pensar y actuar, que la sociedad acepta y revela en sus conductas. Si el Gobierno excluye a grupo de ciudadanos, a los "otros", entonces las políticas de organización los excluirían o exterminarían (Lovón y Pita, 2016), como sucedió en países como Chile que redujo a los nativos selknam, o Argentina, que eliminó, al igual que los EE.UU., a un conjunto de aborígenes. Todo esto demuestra que la realidad en sí es una construcción y acción social; producto de lo que conciben y hacen los hombres.

\section{El poder y el discurso político del presidente de la nación}

En muchos países latinoamericanos, el presidente de la república se elige por sufragio, es decir, a través de la obtención de los votos de las personas que le confieren confianza para gobernar y administrar el país. De acuerdo con la Constitución política del Perú, en el artículo 110, se señala que «El Presidente de la República es el Jefe del Estado y personifica a la Nación» (República del Perú, 1993). En este sentido, como funcionario público, representa, ejerce y ostenta el mayor poder: el 
poder ejecutivo del Estado nacional es el jefe supremo de las Fuerzas Armadas y Policiales del Perú. El cargo que tiene corresponde a la más alta magistratura del país y al funcionario público de mayor jerarquía. Uno de sus roles más importantes es la dirección de las relaciones internas y externas del país. El presidente conduce al país al desarrollo en común, convirtiéndose, de esta manera, en una fuerza ideológica que comunica no solamente los hechos, sino que los comprende y actúa en beneficio de todos los ciudadanos. En su papel de presidente trasmite comunicaciones que son muestra de discursos políticos oficiales respaldados implícita y explícitamente por el poder conferido. Su voz comunica propiamente el discurso político del poder Ejecutivo. El discurso político es el que se genera dentro de los aparatos estatales donde se desarrolla un determinado poder político (Giménez, 1981). Para ello, los políticos tienden a desplegar una serie de estrategias argumentativas encaminadas a concretar sus fines. Los discursos políticos, por ejemplo, responden a la ideología que tiene un cuerpo de políticos (Eagleton, 1997). Siguiendo a van Dijk (2003), una ideología política es aquella que tiene funciones políticas en el campo de la política. Si los políticos establecen una jerarquía entre los ciudadanos, entonces construirán argumentaciones que muestren esa diferenciación y que tendrán efectos no solo sociales ni económicos, sino también políticos, como los territoriales, legislativos o partidarios. De esta forma, ciertos grupos sociales (religiosos, políticos, económicos) buscan prevalecer su discurso para controlar el significado del mundo o posicionarse por encima de otros marginados (por ejemplo, grupos étnicos y feministas). El poder de controlar el discurso es visto como el poder de sustentar prácticas discursivas particulares, asociadas con posturas ideológicas particulares, en un lugar de dominancia sobre otras prácticas alternativas (Fairclough, 1995; van Dijk, 2010).

Cuando un político comunica los hechos de una determinada manera y les confiere el sentido de excluir a parte de la población manifiesta la creencia que le subyace (van Dijk, 2003; Fairclough, 1989). Así, el presidente puede construir una imagen vertical de algunos ciudadanos vistos en contra de los lineamientos del desarrollo del Estado. En consecuencia, sus discursos producen una visión negativa que los identifica en contraposición con el gobierno. Con ello persuade al resto de la población "no excluida" a discriminar, racializar, y oprimir; logra, eficazmente, que sus representaciones ingresen en el "sentido común" de la gente, pues el poder que tiene para construir imágenes de la realidad es legitimado como coherente, racional y de interés mayoritario. De acuerdo con Plantin y Muñoz (2011), «aquel que argumenta no busca pura y simplemente forzar a su interlocutor o imponerle tal creencia o tal actitud por medio de procedimientos manipulatorios. Busca mostrarle que es lógico, razonable, adoptar esta creencia o esta actitud en vista de tal argumento». Es decir, más que forzar cómo pensar, lo que hace el interlocutor, en este caso el expresidente, es hacer creer que trasmite una "realidad" que es lógica y razonable. Las formas de 
"ordenar el mundo" del presidente se naturalizan a través del discurso político que oficializa la manera en cómo el Estado percibe a los ciudadanos y cómo debe operar puntualmente con los "grupos" de ciudadanos que contempla. Propiamente, se trata de un discurso político discriminador.

Según el ordenamiento jurídico establecido en la Constitución, el presidente cumple con asumir veinticuatro deberes, algunos son, a saber: cumple y hace cumplir la Constitución y los tratados, leyes y demás disposiciones legales (inciso 1); vela por el orden interno y la seguridad exterior de la República (inciso 4); ejerce potestad de reglamentar leyes sin transgredirlas ni desnaturalizarlas; y, dentro de tales límites, dictar decretos y resoluciones (inciso 8); y, a su vez, dicta medidas extraordinarias, mediante decretos de urgencia con fuerza de ley, en materia económica y financiera, cuando así lo requiera el interés nacional y con cargo de dar cuenta al Congreso; aunque el Congreso puede modificar o derogar los referidos decretos de urgencia (inciso 19). Es decir, el Presidente dirige la política general del gobierno y la administración del Estado. El poder que posee está encaminado al bien común de la sociedad; por ello, este bien prevalece gracias a los preceptos constitucionales (e incluso a pesar de ellos cuando entran en contradicción con el bienestar de la población).

Ese poder presidencial se devela en las prácticas discursivas: entrevistas, decretos o formulación de leyes y políticas de orden interno que tienen efectos en el escenario político nacional. Estos discursos que emanan de la instancia suprema de regulación política son escuchados y acatados por los organismos del Estado y personas que conforman la sociedad peruana. Por tanto, de un mandatario interesan los discursos emitidos como agente social institucional o jefe de Estado y no como mero individuo, puesto que el papel que cumple está involucrado con la ejecución de políticas; con la relación que establece con los ciudadanos, las empresas y las instituciones públicas. Sus discursos encaminan el orden, y las relaciones internas y externas de la nación, por lo que merecen ser objeto de análisis sobre todo cuando van en contra de la población o sectores vulnerables de la población.

\section{El discurso sobre el Baguazo}

El Baguazo es el término con el que se conoce el conflicto de Bagua (Amazonas, Perú) en el que se enfrentaron, principalmente, las comunidades nativas amazónicas y la Policía Nacional, que se sucedió tras la aprobación de una serie de decretos legislativos, DL 1064 y 1090, que facilitaban la implementación del Tratado de Libre Comercio (TLC) entre el Perú y los Estados Unidos para la promoción de proyectos de inversión, propiamente de corte extractivista, en zonas que afectaban directamente 
a las comunidades nativas de la Amazonía, sin que estas hayan participado en su promoción, a pesar de que el gobierno peruano estaba comprometido, a través del convenio 169 de la Organización Internacional del Trabajo (OIT), a consultar y comunicar a las comunidades indígenas sobre cualquier decreto que pueda concernir directamente a sus tierras. En el caso de Bagua, la minera Afrodita buscaba ocupar una zona protegida legalmente, lo que desató el rechazo de los grupos awajún y wampis, los mismos que demandaron el pedido de derogación de los decretos, que intentaban establecer nuevas formas de administración del territorio indígena. En este contexto es que aparece el discurso de Alan García, como presidente la República se opuso decididamente a los manifestantes; su discurso lo registramos en la siguiente sección.

Dicho discurso, queremos señalar que ha sido cuestionado por los académicos. Según Quiñón y Rodríguez (2016, p. 106), es uno de los discursos políticos confrontacionales por su promoción de la inversión frente altos costos sociales. También, es considerado uno de los discursos excluyentes, pues construye al nativo como un obstáculo para el país. Así, en el estudio de Arrunátegui (2010c, p. 42) se indica que «para el presidente García la ciudadanía de los amazónicos está inconclusa, son "ciudadanos incompletos" y las causas de este déficit son su alejamiento del progreso y el empleo». En la investigación de Méndez (2011, p. 80), se señala que la «protesta de pobladores amazónicos en Bagua, en 2008 y 2009, frente a decretos que ponían en peligro las tierras de comunidades no tituladas revivió en el gobierno de García y sectores afines al proyecto neoliberal el discurso del indio como un 'obstáculo para el progreso'». Las concepciones sobre representar al amazónico de obstáculo y de ciudadano de segunda clase serán develadas en el análisis. Agregamos, además, que el discurso de Bagua se inserta en un discurso mayor conocido como 'El síndrome del perro del hortelano', en el que el mismo exmandatario formula que los grupos aborígenes en general «han insistido en el primitivismo indígena y su oposición a la modernidad, el progreso y el desarrollo" (Méndez, 2011, p. 80).

Asimismo, discursos como el de Bagua se articulan con otros producidos por García al tratar de referirse a las comunidades andinas en su relación con la economía. En su segundo gobierno señaló que «los andinos 'tienen elementos psicológicos de derrotismo', 'son tristes', 'todo está mal siempre' y decir que habitan 'indígenas que cosechan coca todavía'...» (Servindi, 2009). En otro discurso, el exmandatario también infravaloró a la comunidad andina por sus costumbres y la defensa de sus tierras: «Debemos derrotar las ideologías absurdas, panteístas, que creen que las paredes son dioses y el aire es dios. En fin, volver a esas formas primitivas de religiosidad donde se dice: "no toques ese cerro porque es un Apu y está lleno del espíritu milenario y no sé qué cosa”. Bueno, si llegamos a eso, entonces no hagamos nada, 
ni minería» (Redacción IP, 2018). Visto así, el discurso político del expresidente, por inclinarse por prácticas extractivas en la Amazonía y los Andes, registra rasgos de los discursos racistas existentes en el país, que se generan y propalan en la esfera política y en otras también; por ejemplo, en la esfera empresarial, la educativa, etc.

\section{Procedimientos metodológicos}

Se analiza el discurso del expresidente de la República del Perú, Alan García Pérez, emitido en una entrevista local después del paro amazónico del 2009. Su discurso lo profirió tras la muerte de policías en el acontecimiento conocido como "Baguazo", cuyas noticias fueron analizadas por otros especialistas (Arrunátegui, 2010a). Esta entrevista en particular fue realizada fuera del Congreso de la República por un equipo de TV Perú (canal del Estado), América TV, Frecuencia Latina, RPP y otros equipos nacionales (García, 2010). La entrevista se encuentra en el sitio web Youtube. A continuación, transcribimos la entrevista, a la que identificaremos como el "discurso sobre el Baguazo":

Respuesta del presidente Alan García Pérez sobre paro amazónico

1. “QQué puede hacer el Gobierno sino actuar con energía para que el orden, que es un principio

2. Las sociedades piden siempre a los Estados orden. Y ya está bueno, ya está bueno.

3. Pero estas personas no tienen corona.

4. Estas personas no son ciudadanos de primera clase

5. que puedan decir 400000 nativos a 28000000 de peruanos:

6. "Tú no tienes derecho a venir por aquí".

7. De ninguna manera. Es un error gravísimo.

8. Y quien piensa de esa manera quiere llevarnos a la irracionalidad y al retroceso primitivo del pasado...

9. El país no debe en ningún caso ceder a chantajes ni a posiciones de fuerza.

10. Un país que está marchando bien, según los analistas y el mundo,

11. si se deja vencer por pequeños grupos,

12. porque en el fondo son pequeños grupos,

13. que no representan lo más avanzado en el país,

14. entonces es un país que está condenado a detenerse o a retroceder".

(García, 2010).

Este discurso no ha sido estudiado detenidamente. Y hace pensar que la generalización que se pueda realizar de dicho discurso político de 152 palabras no sea válida. Sin embargo, se trata de un discurso significativo, pues fue producido de forma espontánea por el expresidente del Perú en una entrevista en la cual respondía en su rol de mandatario y no en cualquier rol. Nosotros creemos que en la espontaneidad 
se develan y se expresan fácilmente nuestras creencias más que en un discurso planificado y asincrónico en el cual se oscurecen u ocultan. Dicho discurso, además, es significativo porque ha tratado de ser negado: el exmandatario rechaza haber pronunciado un discurso como tal, por lo que entrevistas posteriores ha mostrado su disgusto. Así, en el 2016, molesto por haber sido "mal interpretado" señala que lo «que he dicho es que en nuestro país no hay ciudadanos de primera y segunda» (García, 2016). En el 2018, el líder aprista «se mostró incómodo cuando la periodista Pamela Acosta se refirió a las entrevistas donde García dice que los nativos de Bagua no son ciudadanos de primera clase» (Redacción IP, 2018). Se trata de un discurso que intenta borrar, y no puede, y que a pesar de ser corto, o "mal entendido", ha ingresado en el pensamiento colectivo, que lo recuerda y lo reproduce, incluso a través del espacio virtual, por ejemplo en los foros o Youtube. Para nosotros, el análisis de discursos como el de esta investigación deben ser iniciados frente a los análisis macrodiscursivos en el que estudia varios discursos o discursos en grandes cantidades, puesto que aún de dimensiones menores presentan una riqueza de estrategias lingüísticas con las cuales se construyen significados que impactan en la sociedad.

El discurso que nos convoca al análisis ha sido segmentado en enunciados que constituyen la unidad principal del análisis de la presente investigación; dentro de los enunciados, se analiza las palabras (sustantivos, adjetivos, adverbios), los números (cifras de población), las construcciones sintácticas (las negaciones), las figuras retóricas (la metonimia, la metáfora, la hipérbole) y las voces citadas (la intertextualidad). A través de los enunciados, el interlocutor revela sus formas de pensar. En el análisis de los datos, se utiliza el Análisis Crítico del Discurso (ACD), propiamente buscamos situarnos en el enfoque del discurso político y la retórica. La metodología de este enfoque nos permite estudiar las estrategias léxicas y discursivas empleadas por Alan García. Tales estrategias son estudiadas siguiendo los aportes de van Dijk (2009), Fairclough (1995), Wodak y Meyer (2003). Teniendo en cuenta el ACD, particularmente, las investigaciones de Fairclough (1989), van Dijk (2003), Wodak (2011) y van Dijk y Mendizábal (1999), será posible identificar que el discurso del expresidente es un discurso político que se constituye finalmente como una práctica social que favorece la discriminación y la exclusión. Al respecto, el INCEP (2004) ha señalado que existen aspectos importantes que se deben tomar en cuenta para hacer un buen análisis del discurso político, por ejemplo, la situación de la economía, el entorno social del momento y a quiénes va dirigido el discurso. Así también lo sugieren van Dijk (2005), Wodak (2011), Schäffner y Chilton (2002). No se puede, entonces, dejar al margen las valoraciones económicas que tiene el expresidente de los amazónicos, porque terminan por penetrar en el imaginario colectivo de la sociedad, la cual ve como diferentes a las poblaciones amazónicas, que son apreciadas asimétrica y prejuiciosamente (van Dijk, 1984). 
Finalmente, precisemos que el ACD no propone un diseño metodológico concreto; por el contrario, ofrece una serie de lineamientos que nos ha permitido adoptar procedimientos y herramientas generales de estudio. En la presente investigación, el análisis realizado se estructura a partir de dos creencias que se infieren de la lectura del discurso y del análisis propio de las estrategias lingüísticas.

\section{Análisis de los datos: El discurso de discriminación del expresidente como una práctica social}

\subsection{Creencia 1: Entre dos clases de ciudadanos, los amazónicos son ciudadanos de segunda clase}

\subsubsection{El concepto de ciudadano}

Alan García negó la ciudadanía a los amazónicos, como se registra en las líneas 3 y 4 de su discurso, de la siguiente manera: "Pero estas personas no tienen corona. Estas personas no son ciudadanos de primera clase". La RAE (2001) define en el diccionario la palabra "ciudadano", en su tercera acepción, como el «habitante de las ciudades antiguas o de Estados modernos como sujeto de derechos políticos y que interviene, ejercitándolos, en el gobierno del país». En su última edición (RAE, 2014), define "ciudadano" de la siguiente manera: «Persona considerada como miembro activo de un Estado, titular de derechos políticos y sometido a sus leyes». Es decir, para la edición 2001, un ciudadano es aquella persona que tiene derechos y los usa dentro de un país o una sociedad; para la edición 2014, además, se somete a las leyes existentes; cabe señalar que si una persona incumple la ley no significa que pierda la condición de ser ciudadano: el ciudadano tiene deberes como derechos. En el Perú, son ciudadanos todos: tanto la gente que puebla la Costa, como la que puebla la Sierra y la Selva. Todos los peruanos son titulares de derechos políticos. Entre tales derechos se encuentra el derecho de votar, el derecho a ser votado o participar en una elección, el derecho a ser representado, el derecho a participar políticamente en los asuntos del Estado o acceder a las funciones públicas (Rosillo y Bustamante, 2014). Tras la resistencia amazónica al decreto supremo que vulneraba las tierras de la zona del Cenepa, el presidente señaló que "estas personas no son ciudadanos de primera clase"; es decir, no eran tratados como ciudadanos con goce de derechos políticos como los demás. Pero también en su discurso subyace la negación de otros derechos, por ejemplo los derechos civiles, el de garantizar la integridad de las personas, la vida, la seguridad, la libertad de opinión y la protección de toda discriminación en base a la raza, color, etnia. No solo se les negaba todo vínculo formal con el Estado, sino también se les hacía ver que no podían integrarse al Estado o no podrían "dis- 
frutar" de los derechos que un Estado les otorga. En virtud de ello, establecía que había dos clases de ciudadanías: una de primera clase y una de segunda clase. La primera se caracteriza por tener derechos políticos y otros, mientras que la segunda, según el discurso del expresidente, está desposeída de estos o los ha perdido. La "otra ciudadanía" la construye en el discurso, como veremos más adelante, con el uso de ciertos vocablos con los que se les atribuyen a los amazónicos características negativas que configuran su ser social, las mismas que generan en consecuencia una manifestación de racismo cultural y exclusión social. El presidente, los policías, los medios de comunicación y la gente de la costa pertenecerían, por ende, a la primera clase, en contraste con los nativos amazónicos, quienes, junto incluso con los nativos de los Andes, pertenecen a la segunda clase. La primera clase goza de privilegios, está protegida por la ley, es ordenada y racional; la segunda carece de derechos, está desprotegida, es caótica, es irracional; es decir, está subordinada, por lo que es valorada como una ciudadanía incomprensible e inconcebible. Los nativos no pueden reclamar; así lo reprocha García en la línea 6: ellos no pueden decir "tú no tienes derecho a venir por aquí". Despojados de cualquier derecho político y civil, para el expresidente, los grupos amazónicos no pueden negarse a la presencia del Estado, la policía y la empresa. De esta manera, la "modernidad" con su apreciación juiciosa de "ciudadanía" alimenta una vez más los mitos de salvajismo sobre los amazónicos (Pizarro, 2009). Alan García logra categorizar negativamente a los aborígenes amazónicos a través de una estrategia léxica que sirve para hacerlos ver de "salvajes" y posicionar a los no amazónicos como verdaderos ciudadanos. La categorización cala en el discurso (van Dijk, 2003). En su argumentación, el uso de la palabra "ciudadano" genera un impacto en el imaginario colectivo. El discurso de García es, por tanto, una muestra de los discursos jerarquizantes, que devienen de la colonia y se proyectan hasta la República, que se ha aprendido y se sigue aprendiendo (Bhabha, 1994). Entonces, en su discurso se devela una creencia social.

Cabe señalar que ante el Derecho Constitucional todas las personas tienen la misma calidad de derechos (Bermúdez, 2001, p. 338). Sin embargo, hoy, por la influencia de la globalización, los cambios económicos actuales y la desigualdad económica y social creciente entre los grupos sociales, no todas las personas gozan de la misma manera los derechos fundamentales. Dichas diferencias han generado que en el Perú se discuta tres tipos de ciudadanías: la ciudadanía plena, que no admite limitación alguna en el ejercicio de derechos civiles, políticos, sociales, económicos, culturales y lingüísticos; la ciudadanía de segunda clase, en la que se encuentra un sector de la población que no puede gozar de la totalidad de tales derechos; y la ciudadanía de tercer grado, que está constituida por la población catalogada como niño y adolescente. Es interesante encontrar en este autor que en el Perú la ciudadanía de segunda clase está relegada del desarrollo nacional. Para Bermúdez (2001, 
p. 338), en «la actualidad, el sector humano que lo integra son las poblaciones que viven en las zonas rurales de la nación porque tienen un status que las 'limita' y las hace poseedoras de un falso reconocimiento de derechos de parte del Estado y de la comunidad hegemónica». Es decir, la ciudadanía de segunda clase se halla impedida de aprovechar de lleno sus derechos de ciudadanía porque han sido relegadas por el mismo Estado.

\subsubsection{Yo y ellos}

La legitimación de las clases de ciudadanía se refuerza en la construcción de un nosotros positivo, frente a un ellos negativo (van Dijk, 2003). La argumentación busca justificar las atribuciones positivas y negativas de unos y otros (Wodak y Meyer, 2003, p. 114). Según García, los nativos amazónicos, "ellos", los "otros”, son situados de "irracionales" y "primitivos", es decir, son representados como seres inferiores al "nosotros" o "yo" "racional" y "moderno", que, en este caso, se asume como un Estado monocultural y occidental superior. Esa diferenciación se manifiesta en su propia declaración (línea 8) cuando establece un "nosotros" en contraposición con un "otros": "Y quien piensa de esa manera quiere llevarnos a la irracionalidad y al retroceso primitivo del pasado". Para el expresidente, ese "ellos", ese otro grupo, que supuestamente busca conducirnos a la irracionalidad, está constituido por una clase social minoritaria, a la que califica de "pequeños grupos" (líneas 11 y 12), haciendo notar que los occidentales son el grupo mayoritario, el cual busca evacuar cualquier tipo de obstáculo: sea mayúsculo o minúsculo (Silva, 2008), sin valorar la diversidad de la población amazónica, que constituyen entre 50 a 70 grupos étnicos. El expresidente hizo ver que ser pocos es negativo porque va en contra del "deseo" de la mayoría. Además, hacía ver que al ser un número insignificante era fácil controlarlos, ignorarlos o detenerlos. La representación de ese "otro" negativo es dibujada además cuando se hace uso de sustantivos y adjetivos calificativos, tales como "primitivos" o "irracionales", que se emplean para categorizarlos de ciudadanos inferiores como se precisa en el siguiente apartado.

\subsubsection{Sustantivos y adjetivos "negativos"}

Las características atribuidas a la supuesta ciudadanía de segunda clase o segunda clase social están referidas a rasgos de racialización colonial. Para el presidente, la forma de pensar de los amazónicos "lleva a la irracionalidad", al "retroceso", porque representa lo "pasado" (línea 8). En otras palabras, en el discurso de Alan García, son "irracionales", "atrasados" y "prehistóricos". El ciudadano de la primera categoría, en contraposición, representaría "la modernidad" y la "ciudadanía correcta". Estas relaciones hegemónicas se construyen sobre la base de una otredad negativa: 
aislándola, hostigándola y reprimiéndola. Los sustantivos negativos son un medio para la construcción de imaginarios nocivos y prejuiciosos. Como indica van Dijk (1984), el prejuicio aparece en los discursos contra las minorías.

En la categorización de las clases sociales, debe indicarse que los españoles y otros europeos consideraron a los pueblos de la selva como "salvajes", "animales", "arcaicos", "primitivos", argumentos que fueron heredados por la mayoría de sociedades del mundo y que fueron utilizados para superponerse a los nativos: quienes supuestamente están para servir y para entregar sus tierras al grupo colonizador (Mendes, 1992). Estos “conquistadores" encontraron resistencia, por lo que siempre los percibieron de "salvajes" y "bravos" (Alimonda et. al 2009; Bisbe 2009). No resulta extraño que los conquistadores valoraran a los pueblos amazónicos como menos "civilizados" que los pueblos andinos (Pineda, 2005). Este discurso histórico es usado por García, quien llama "primitivos” a los amazónicos (línea 8), también usa palabra "nativos" en forma despectiva (línea 5). Dichas valoraciones se transmiten y conforman una representación socialmente compartida que los no amazónicos poseerán sobre el grupo étnico.

Asimismo, del discurso de García se desprenden un conjunto de adjetivos, que sin aparecer expresos, se infieren. Sobre la base de sus declaraciones, los amazónicos serían "caóticos" (el orden, que es un principio, línea 1), "inciviles" y "marginales" (no son ciudadanos de primera clase, línea 4), "chantajistas" y "belicosos" (el país no debe en ningún caso ceder a chantajes ni a posiciones de fuerza). A la vez, se hallan “condenados" (es un país que está condenado, línea 14), "desprivilegiados" (estas personas no tienen corona, línea 3) y "atrasados" (no representan lo más avanzado en el país, línea 13). Una vez más, la clase social bosquejada por el expresidente peruano es categorizada de inferior con el fin último de ser expectorada. Desde la teoría de la basurización simbólica, el "otro" basurizado debe ser evacuado para que el sistema funcione. Dicha basurización opera mediante discursos cuyas lógicas se originan en la condición patriarcal y colonial (Silva, 2008, p. 18). En tal sentido, la otredad, donde subsisten "los segundos ciudadanos", es rechazada, denigrada y evacuada.

\subsubsection{Polarización}

En el contexto de la clasificación de los ciudadanos, García polariza la información entre un "siempre" y un "ningún". En el primer caso, el adverbio "siempre" resalta la idea de que los Estados brindan el orden necesario (línea 2). Ese "siempre" confiere la idea de "totalidad", con la cual se construye el argumento de que la sociedad en general busca que el Estado intervenga; es decir, su responsabilidad en asuntos conflictivos termina por considerarse legal y exigida. Sin embargo, ese "siempre" es excluyente, porque no incluye a los nativos amazónicos como parte 
de la sociedad. Es interesante también notar que en la argumentación la imagen del Estado va unida con la idea de "orden". Una vez más, la cultura occidental se representa de racional y ordenada.

En el caso del adjetivo indefinido "ningún", se evidencia también una polarización (línea 9). El Estado, para el expresidente, estaría siendo amenazado por un grupo "chantajista", que ejerce la "fuerza". No obstante, el Estado es quien detenta el monopolio del poder, y no los "pequeños grupos", a los que intenta controlar. De esta manera, la polarización genera reacciones adversas, prejuiciosas y racistas por parte de los oyentes y lectores de la noticia contra los nativos amazónicos. En tal caso, la palabra "ningún" enfatiza la posición que tuvo García como jefe del Estado. Dicho adjetivo, además, está vinculado con la referencia a "país". En la argumentación de García, el "país", bajo la figura retórica de la abstracción discursiva, es el que desaprueba los accionares de los amazónicos o el que se rehúsa al reconocimiento de sus derechos políticos y civiles.

Según van Dijk (2005, p. 34), cuando las ideologías son proyectadas sobre el discurso pueden expresarse en estructuras subyacentes como la polarización en la que se describe positivamente al grupo endógeno y negativamente al grupo exógeno; dicha polarización tiene lugar a través de manipulaciones discursivas, por ejemplo mediante las lexicalizaciones o los movimientos semánticos como los negadores y otros movimientos argumentativos que dan o quitan énfasis a las cosas buenas y a las cosas malas, vistos claramente en el discurso de García.

\subsubsection{La metonimia}

Para legitimar su discurso, Alan García habla desde una entidad abstracta: el Gobierno. Es decir, no habla en primera persona ni toma la responsabilidad discursiva. Se oculta en el "Gobierno" (línea 1), e incluso en el "país" (línea 9). Él recurre a una figura de la retórica, que es la metonimia, la cual le permite designar una cosa con el nombre de otra con la que mantiene una relación de contigüidad lógica. Así, designa su persona con el nombre de la entidad política que dirige, con el fin de mitigar su propia voz. En el discurso político, se recurren a sujetos abstractos, a partir de la metonimia, para a despersonalizar al "otro" a la vez que quitar la propia responsabilidad del enunciador, cuya imagen pública puede encontrarse altamente amenazada (Salerno, 2012, p. 90). De tal modo, cuando establece la categorización de la ciudadanía por clases, no la realiza explícitamente en primera persona, sino más bien en tercera persona, empleando para ello la entidad del Gobierno, lo cual ocasiona que esta sea la que asuma, produzca y legitime la división de clases, en la que los nativos amazónicos aparecen ubicados en una posición desfavorable. La responsabilidad cae así sobre el Gobierno y no sobre el emisor. Según Eagleton 
(1997, p. 83), la legitimación establece los propios intereses de un poder dominante como algo aceptable en general. Para Chilton y Schäffner (2000, p. 306), la legitimación sienta el derecho de ser obedecido, mientras que la deslegitimación presenta al "otro" negativamente: lo culpa, lo acusa, lo insulta. El recurrir a la entidad "Gobierno" determina que la sociedad busque que el grupo adverso obedezca y asuma las consecuencias del castigo.

En la argumentación de García, el "Gobierno" aparece también junto con la expresión "actuar con energía” (línea 1), lo que significa que el emisor busca legitimar el monopolio del poder con el que cuenta. En tal sentido, el "Gobierno" como una entidad "abstracta" maneja la fuerza jurídica, política y armada, es decir, la coerción y la coacción, dos acciones concentras en el desenvolvimiento de los hechos políticos de Bagua, en el que ocurrió, en medio del enfrentamiento, matanzas entre nativos y autoridades policiales. En dicho contexto, el aparato ideológico estatal buscó deslegitimar a través de la entidad del "Gobierno" al grupo amazónico awajún (Arrunátegui, 2010a).

\subsubsection{La negación}

Según el presidente, los amazónicos "no tienen corona” (línea 3). Al igual que el resto de la población, estarían en la condición de acatar las decisiones del gobierno. Es decir, al ser partícipes de una nación o de un Estado, no tienen privilegios. Sin embargo, este discurso niega la historicidad del amazónico, quien vive y reside en los territorios de la selva, conservando la ecología y administrando la distribución de la tierra. Decirles que "no tienen corona" implica eliminar sus derechos de ciudadano, es, pues, rechazar sus derechos de pensar y actuar en su propio bienestar. Para García, ellos no pueden oponerse al proyecto minero, propiamente a la inversión de la minera Afrodita, a pesar de que las actividades mineras traen consigo la destrucción de los bosques, la contaminación de los ríos y la muerte de los pobladores. Para el exmandatario, tampoco con ellos se puede dialogar. Es decir, los pueblos amazónicos, e incluso los pueblos andinos, se encuentran obligados a acatar la decisión estatal, sin necesidad de hacerles una consulta previa en leyes que los involucren o continuar en alguna negociación. Dicha negación corresponde a ciertas apreciaciones que refuerzan las relaciones de la otrificación o las relaciones de poder (Wodak y Meyer, 2003). Según Chilton y Schäffner (2000), se deslegitima al adversario y se victimiza el propio grupo.

El expresidente utiliza otras negaciones, tales como "no son ciudadanos de primera clase" (línea 4), "tú no tienes derecho a venir por aquí" (línea 6), "el país no debe en ningún caso ceder a chantajes ni a posiciones de fuerza" (línea 9) y "no 
representan lo más avanzado en el país" (línea 13). Tal estrategia sintáctica opera en el plano del discurso para reforzar negaciones de posibles imágenes positivas vinculadas con los derechos fundamentales de las personas, el derecho de la ciudadanía, el derecho de libre tránsito, el derecho de participación en las actividades económicas, políticas y sociales, y los derechos al propio desarrollo y a la educación. La negación busca entonces rechazar sus derechos, y verlos como sujetos nocivos para el Estado. Según van Dijk (2003, p. 64), la estrategia de la negación protege la autoimagen positiva del emisor y su grupo.

\subsubsection{Number game}

En el discurso de Alan García se infiere que las poblaciones amazónicas no tienen derechos porque representan una menor cantidad de población territorial: "que puedan decir 400000 nativos a 28000000 de peruanos" (línea 5). Al ser vistos como pocos, no tendrían razón para impedir los proyectos estatales. Se responsabiliza al "otro" minorizado de los obstáculos de la inversión y de las consecuencias del propio conflicto. En otro sentido, García minoriza al grupo amazónico usando cantidades numéricas de población, que no han sido corroboradas estadísticamente, sino que salen de una entrevista cuasiespontánea. De acuerdo con él, el grupo amazónico que participó en el conflicto de Bagua fueron unos 400000 nativos frente a los 28000 000 peruanos; esta última cifra indicaba el total de peruanos que vivían en el país (actualmente, según el censo 2017, hay casi de treinta y dos millones de población en el Perú). Sin embargo, tal estrategia busca discriminarlos y excluirlos, porque los pobladores del Perú para el año mencionado eran aproximadamente 28000000 , dentro de los cuales se encontraban los 400000 amazónicos a los que hace referencia, pero que el exmandatario los hace ver como un conjunto de sujetos que no pertenecen al todo. Entonces, los grupos amazónicos en general, aun cuando propiamente hayan participado los awajún y wampis, son asumidos como un grupo expectorado. Siguiendo su argumento, los nativos no conformarían parte de la población peruana, sino de un grupo pequeño (línea 11 y 12) que busca desarmonizar las relaciones estado-población. Este argumento nos remite a una de las estrategias que, según van Dijk (2010, p. 91), se usa en los diarios: the Number Game (se mencionan grandes cantidades numéricas con el fin de realzar ideas de crisis, peligros o amenazas, sin dejar de sugerir precisión y objetividad). Para Van Dijk (2009, p. 341), "una famosa estrategia de argumentación es, justamente, el juego de los números". El juego de los números, para el autor, desempeña algunas funciones discursivas, tales como transmitir ideas de objetividad y precisión con el fin de lograr la credibilidad. Al especificar las cantidades de peruanos en contraste con las de los nativos, García intenta mostrar su rechazo y crear un sentimiento de pánico. Genera así una negatividad hacia estos "400 000 nativos" considerados de algún modo como "no peruanos". A esta otra 
ciudadanía representada como reducida y sectorial se le despoja de sus derechos, porque pertenece a la clase que no es la mayoritaria y beneficiada. Respecto de la cifra de los 400000 nativos, asimismo, el expresidente no indica de dónde extrajo el dato. En ese entonces, la población awajún no pasaba de los 45000 y la población total de la Amazonía no pasa de los 4 millones. En otro sentido, la cifra citada por García parece responder a un mecanismo argumentativo de lanzar una cifra, sobre todo, inflada para crear un discurso basado "científicamente" en números o cantidades que impacte en el interlocutor. Para Perelman y Olbrechts-Tyteca (1989, p. 239), «las cifras absolutas hablan con más viveza a la imaginación». Siguiendo a van Dijk (2009, p. 342), el juego de los números es una estrategia que favorece la autorepresentación positiva y construye la heterorepresentación negativa. Después de siete años, el expresidente también mostrará su rechazo hacia los grupos amazónicos al infravalorar el número de muertos (García, 2016). En un nuevo discurso, los amazónicos son cuantificados como "10" "pobladores" y nombrados después de las víctimas policiales, a los que se les considera de más valiosos en tanto en cuanto el expresidente usa enfáticamente el conector "en primer lugar" para clasificar a los actores sociales implicados en el Baguazo: «Se habla y se habla de Bagua. Acuérdense todos que lo que ocurrió fue la muerte de más de 20 policías. Hubo una reacción evidente de la Policía y murieron 10 pobladores, todo es lamentable, pero la verdad es que si hubo un error allí, fue extender demasiado el diálogo. Tal vez actuando con energía en el primer momento se hubieran ahorrado las vidas de esos Policías en primer lugar». En dicho discurso, la cifra sirve para representar negativamente a los "otros" y empoderar a un "nosotros" autoridad. Cabe indicar que García cree el diálogo prolongado fue un "error”. En otras palabras, con los amazónicos no se debía interactuar, sino, una vez más, "imponer”.

\subsection{Creencia 2: El crecimiento económico es obstaculizado por grupos primitivos como los amazónicos}

\subsubsection{La metáfora}

Una segunda creencia que se halla presente en el discurso de García es aquella que considera que el crecimiento de la economía es detenido por grupos primitivos como los amazónicos. Ello se devela en la metáfora que emplea el expresidente en su discurso (líneas 10-14). La metáfora que García bosqueja es la siguiente: "el país es un vehículo". Si marcha bien, es porque hay inversión económica que es aceptada por toda la población, pero marcha mal cuando la inversión es obstaculizada por algunos grupos de personas. Es decir, no se moviliza porque los amazónicos constituyen una barrera para las decisiones y acciones estatales y empresariales. En este caso, la metáfora sirve para expresar que el país es un vehículo que no debe dejarse 
detener ni vencerse por nadie, sino que debe avanzar pese a la existencia de oposiciones. Entonces, en el discurso del expresidente subyace una creencia relacionada con aspectos económicos. Visto así, la metáfora como una de las estrategias discursivas es una estrategia socorrida de los políticos en sus discursos (García, 2004).

Sobre la base de la metáfora "el país es un vehículo", García nos dice que los amazónicos condenan al país a dos vías: a estancarse o retroceder (línea 14). Considera que no aceptan formar parte del proyecto económico y el avance de la nación peruana. De acuerdo con Arrunátegui (2010b, p. 449), al parecer, al amazónico todavía no se le ha perdonado su resistencia al proyecto asimilacionista. En tal sentido, siempre se lo percibe como el otro ciudadano que impide el progreso de los demás, porque se le considera que no se encuentra acostumbrado a la modernidad, o no quiere acceder a tal supuesta nueva vida. Al resistirse, los no nativos los discriminan y racializan, por lo que se representan e identifican por ejemplo de opositores al crecimiento económico. Para García, los recursos son, pues, de todos los peruanos y no de este grupo de ciudadanos; en otro sentido, se reproduce un discurso que sostiene que las tierras están para ser empleadas con el fin de crecer económicamente, sin que se cuestione el tipo de economía asumida, y la exclusión y deterioro que origina.

\subsubsection{La hipérbole}

Como el expresidente quiere dejar en claro que los amazónicos son un óbice para el crecimiento económico del país, él recurre a la idea de representarlos desproporcionadamente como individuos opuestos a la actividad estatal y empresarial, particularmente a la inversión. Para él, los proyectos mineros son detenidos por grupos que "no representan lo más avanzado en el país" (línea 13). En tal caso, utiliza una hipérbole, es decir, una figura retórica que se emplea para exagerar las características, cualidades u otros aspectos atribuidos a una persona o un hecho, con el fin de captar la atención, en este caso, con miras de lograr construir una imagen negativa de los amazónicos. Al conseguir una mayor fuerza expresiva consigue, a la vez, una mayor fuerza persuasiva (Perelman y Olbrechts-Tyteca, 1989). Según García, los nativos de la Amazonía son "primitivos" y están "atrasados" o en "retroceso", por lo que no son como los ciudadanos costeros, que al igual que él forman parte de lo más avanzado en el país; es decir, forman parte del grupo que favorece el crecimiento económico.

En la línea de enfatizar que los nativos amazónicos se oponen a la inversión económica, el expresidente construye la idea de que ellos evitan la inversión minera a todas costas. No resulta extraño que utilice otra hipérbole para dañar la imagen del "otro"; esta vez a través del superlativo -ísimo. En el discurso de García, se indica que 
la defensa de los pueblos indígenas, propiamente la de las etnias awajún y wampis, opuestos a la minera Afrodita en una zona protegida legalmente, constituye, para él, "un error gravísimo" (línea 7). Para García, la inversión es más importante que la salud, la vida y el espacio de los pueblos amazónicos, a los que asume naturalmente de ciudadanos irracionales o ciudadanos de segunda clase. La superlación pondera en grado máximo la situación descrita hasta intensificar la idea de reproche o rechazo (Arboleda, 1992, p. 72).

\subsubsection{La intertextualidad}

El presidente García, utilizando la estrategia discursiva de la intertextualidad (Fairclough, 1995), refuerza la imagen negativa de los amazónicos como opuestos a la inversión económica al citar a un conjunto de especialistas a los que llama "analistas" e incluso al citar al "mundo". Él los cita de la siguiente manera: "según los analistas y el mundo" (línea 10). De este modo, valida su discurso, porque busca mostrar un respaldo que sostenga su argumento. En tal caso, la validación la formula a partir del nombramiento de los "analistas" y todas las personas del "mundo". García a través de la generalización originada por la intertextualidad genera que los "analistas" aparezcan como la voz autorizada que tienen el poder de determinar quiénes se obstaculizan el "desarrollo económico".

La intertextualidad también es empleada cuando el expresidente construye la voz de los pueblos amazónicos. Para él, los nativos estarían diciendo que nadie puede pasar por los territorios de la Amazonía. García los parafrasea de la siguiente manera: "Tú no tienes derecho a venir por aquí" (línea 6). Sin embargo, en ninguna declaración anterior o posterior al Baguazo, los pueblos amazónicos sostendrán dicho discurso; al menos no, expresamente. Tal como los mismos amazónicos afirman, ellos no se oponen al progreso del país, ellos buscan participar en las decisiones y acciones que involucra a sus tierras y a sus etnias.

Para el expresidente, la Amazonía está para ser usada, para despojarla de los recursos en beneficio de la población. Al respecto, debemos señalar que si el uso de la tierra no se realiza sin las medidas de control y preservación del ecosistema, las consecuencias que podría ocasionar a las poblaciones étnicas serían irreparables. No en vano los pueblos amazónicos levantaron una marcha de rechazo que se desencadenó en la matanza de policías y nativos. La utilización de la Amazonía, la resistencia inútil de los nativos y la prosperidad económica del país alimentan la creencia del expresidente de que los amazónicos retardan el progreso económico. Para el presidente representan el retroceso: no aceptan aquello que el resto de la población legitima. 


\section{Conclusión}

El discurso del expresidente Alan García construye, como se ha visto, una representación negativa de los amazónicos, discurso que tiene el poder de reproducir prácticas sociales de desprecio en la sociedad, puesto que el expresidente influye en la audiencia que lo escucha, y logra con ello una naturalización de que los amazónicos son "incivilizados", "irracionales", "primitivos" y "retrasados". Tales rasgos configuran la creencia de que existe un "ciudadano de segunda categoría". Al ser "otrificado negativamente", los pueblos amazónicos son repudiados en el imaginario colectivo de la sociedad peruana, convencida de que son agentes opositores del crecimiento económico y, en consecuencia, de la modernidad. La creencia de la "ciudadanía de segunda clase" se alimenta, a su vez, de la idea de que son "ciudadanos opuestos al progreso económico". En sí, la creencia de la segunda ciudadanía descansa en la concepción del modelo económico que tiene García, y que predomina en las economías liberales de América Latina, quien considera que una sociedad, en el fondo "el desarrollo de una sociedad", se define por su crecimiento económico. Es decir, sin este, las sociedades no existen. Dichas creencias, como se ha visto en este trabajo, se descubren en el examen de las estrategias léxicas y discursivas presentes en el discurso del exmandatario.

El discurso del expresidente, más allá de ser mero texto, constituye una práctica social que busca discriminar y excluir, pues tiene el poder de construir, a partir de la palabra, una realidad sobre los grupos amazónicos y la Amazonía, y de influir en la audiencia que lo sigue. Su discurso busca hacer real aquello que asume: la otredad es negativa. En tal sentido, los discursos identifican, representan relaciones y producen ideologías que se aceptan y nos conducen socialmente. De esta forma, las empresas y otras entidades estatales y privadas se oponen a los amazónicos y los ven como seres inferiores que deben ser colonizados, al igual que sus tierras. Así, en el documento La Sentencia del Caso Baguazo y sus aportes a la justicia intercultural, la CNDDHH (2017, p. 18) señala que «en las leyes de colonización de 1898 y 1909, el Estado republicano consideraba las tierras amazónicas como res nullius, sin reconocer a los indígenas ningún derecho de propiedad sobre aquéllas. De esta manera, las entregaba en concesión a extranjeros y peruanos con derechos civiles». En otras palabras, para el Estado peruano la población amazónica no es una prioridad de la agenda nacional, o simplemente no existe.

Sin embargo, si queremos un país que integre a todos, debemos transformar nuestros procesos de construcción identitaria, considerando que el "otro" forma parte del "nosotros". Debido al poder que posee un presidente, es crucial tomar conciencia de leer críticamente sus discursos, sin perder de vista que bajo su rol se crean, recrean, reproducen y legitiman una serie de ideologías que conducen 
a pensar y aceptar el tipo de ciudadano y el tipo de crecimiento que requieren un país. Asimismo, tenemos que entender que las prácticas sociales que desarrollan en nuestra sociedad nos involucran, por lo que somos responsables de sus efectos. Por tanto, debemos crear prácticas sociales que eliminen la discriminación, la exclusión, la colonización y racialización en general.

Por último, no podemos determinar que el expresidente Alan García sea racista, lo que sí podemos indicar es que su discurso lo es, particularmente por la lectura económica que tiene del mundo globalizado, en el que se categoriza las ciudadanías, las naciones, los países y los continentes, unos más valorados que otros. Son los discursos los que narran la racialización y tienen poder para construir o destruir las relaciones étnicas, culturales, políticas, sociales, económicas. Dicho discurso tampoco es único del expresidente, sino de toda una sociedad (van Dijk, 2010) que produce y reproduce la representación asimétrica de los grupos amazónicos. Por tanto, sería interesante que los analistas del discurso crítico examinen los discursos asimilados por la sociedad peruana sobre el Baguazo con el fin de medir el impacto que tienen las ideologías extractivas; uno de esos espacios son las redes sociales y foros, en los que apareció comentarios a favor o en contra de las medidas del exmandatario.

\section{Referencias bibliográficas}

1. Alimonda, H. et. al. (Ed.). (2009). La Amazonía rebelde. Lima, CLACSO, Programa Democracia y Transformación Global, Confederación Nacional de Comunidades del Perú afectadas por la Minería, Cooper Acción, UNMSM, Facultad de Ciencias Sociales.

2. Arboleda, D. (1992). La intensificación de las locuciones de la prensa escrita de Medellín: una aproximación pragmática. Lingüistica y Literatura, 62, 63-85. Recuperado de https://bit.ly/2Mlttp0

3. Arrunátegui, C. (2010a). Ideología y prensa escrita en el Perú: el caso Bagua. Lexis, 34(2), 353 368. Recuperado de http://bit.ly/14rDeJ.

4. Arrunátegui, C. (2010b). El racismo en la prensa escrita peruana. Un estudio de la representación del Otro amazónico desde el Análisis Crítico del Discurso. Discurso \& Sociedad, 4(3), 428-470.

5. Arrunátegui, C. (2010c). El racismo en la prensa escrita peruana. Un estudio de la representación del Otro amazónico desde el análisis crítico del discurso. Tesis para optar el grado de magíster en Lingüística. Lima, Pontificia Universidad Católica del Perú.

6. Bermúdez, M. (2001). Categorías de ciudadanos en el Perú, por el goce de derechos fundamentales. Boletín del Instituto Riva-Agüero, 28, 333-343.

7. Bhabha, H. (1994). La otra pregunta. El estereotipo, la discriminación y el discurso del colonialismo. El lugar de la cultura. Buenos Aires: Ediciones Manantial SRL, 91-110.

8. Bisbe, L. (2009). Huellas del racismo antiindígena en textos escolares venezolanos de finales de los años ochenta. Núcleo, 26, 11-35. Recuperado de https://bit.ly/2MuUB4a

9. Chilton, P. y Schäffner, C. (2000). "El discurso como interacción en la sociedad". van Dijk, T. (Comp.). El discurso como interacción social. Estudios del discurso: introducción multidisciplinaria. Barcelona: Gedisa, 297-329. 
10. CNDDHH (Coordinadora Nacional de Derechos Humanos) (2017). La Sentencia del Caso Baguazo y sus aportes a la justicia intercultural. Lima, Diakonia. Recuperado de http://bit.ly/2E3JAiQ

11. Eagleton, T. (1997). Ideología. Barcelona: Paidós.

12. Espinosa de Rivero, O. (2009). ¿Salvajes opuestos al progreso?: Aproximaciones históricas y antropológicas a las movilizaciones indígenas en la Amazonía peruana. Anthropologica, 27(27), 123-168.

13. Fairclough, N. (1989). Language and Power. Londres y Nueva York: Longman.

14. Fairclough, N. (1992). Discourse and Social Change. Cambridge: Polity Press.

15. Fairclough, N. (1995). Critical Discourse Analysis: The Critical Study of Language. Londres y Nueva York: Longman.

16. Foucault, M. [(1969) 1990]. La arqueología del saber. Madrid: Siglo XXI.

17. García, A. (19 de enero de 2016). Alan García: el error en Bagua fue extender el diálogo. La República. Recuperado de https://bit.ly/2MQBUF2

18. García, A. (2010, julio 7). Alan García - indígenas: ciudadanos de segunda clase [Archivo de video]. Recuperado de http://bit.ly/h3bibt

19. García, A. (28 de octubre de 2007). El síndrome del perro del hortelano. El Comercio.

20. García, D. (2004). La metáfora en el discurso político. Revista Reflexiones. 83 (2), 61-72.

21. Giménez, G. (1981). Poder, Estado y Discurso. México. Dirección General de Publicaciones. Ciudad Universitaria México D. F.

22. INCEP (Instituto Centroamericano de Estudios Políticos) (2004). Discurso Político. Guatemala: Cuadernos de Formación para la Práctica Democrática, 9.

23. Lovón, M. y Pita P. (2016). Los términos de la crisis venezolana. Boletín de Lingüística, 28(4546), 70-110. Recuperado de https://bit.ly/2Gj2LKP

24. Mendes, Ch. (1992). La Amazonia sin mitos. OTCA, BID, PNUD.

25. Méndez, C. (2011). De indio a serrano: nociones de raza y geografía en el Perú (siglos XVIIIXXI). Histórica, 35(1), 53-102. Recuperado de https://bit.ly/2L0RhsK

26. Perelman, Ch. y Olbrechts-Tyteca, L. (1989). Tratado de la argumentación. La nueva retórica. Madrid: Editorial Gredos.

27. Pineda, R. (2005). La historia, los antropólogos y la Amazonía. Antípoda. Revista de Antropología y Arqueología, 1, 121-135.

28. Pizarro, A. (2009). Amazonía: el río tiene voces. Santiago: Fondo de Cultura Económica.

29. Plantin, C. y Muñoz, N. (2011). El hacer argumentativo. Buenos Aires: Biblos.

30. Quiñón, A. et. al. (2016). Presidentes en problemas: Aprobación presidencial de Alan García (2005-2011) y Ollanta Humala (2011-2016). Politai: Revista de Ciencia Politica, 7(13), 93-119. Recuperado de https://bit.ly/2MW56Lb

31. RAE (Real Academia Española) (2014). Diccionario de la lengua española. Madrid: Espasa-Calpe.

32. RAE (Real Academia Española) (2001). Diccionario de la Real Academia Española. Madrid: Espasa-Calpe.

33. Redacción IP (30 de abril de 2018). “Alan García sobre nativos del Perú: ‘Estas personas no son ciudadanos de primera clase"”. Informateperu.pe. Recuperado de https://bit.ly/2OHQEXs 
34. República del Perú (1993). Constitución política del Perú.

35. Rosillo, A. y Bustamante, G. (2014). Derechos políticos como derechos fundamentales. Regulación internacional y local. San Luis Potosí: Consejo Estatal Electoral y de Participación Ciudadana.

36. Salerno, P. (2012). Lingüística: Metáfora y metonimia: el discurso y la conferencia de prensa de Cristina Fernández de Kirchner. Texturas, 1(12), 79-92. Recuperado de https://bit.ly/2OGqVi5

37. Schäffner, C. y Chilton, P. (2002). Politics as text and talk: analytic approaches to political discourse. Ámsterdam: John Benjamins Publishing Company.

38. Servindi (Servicios de Comunicación Intercultural) (2009). Perú: Señalan 'el peligroso racismo de Alan García'. Video de antología 2009. Recuperado de https://bit.ly/2MkPzIx

39. Silva, R. (2008). El factor asco. Basurización simbólica y discursos autoritarios en el Perú contemporáneo. Lima: Red para el Desarrollo de las Ciencias Sociales en el Perú.

40. Trujillo, P. (2001). Salvajes, civilizados y civilizadores. La Amazonia ecuatoriana. El espacio de las ilusiones. Quito: Fundación de Investigaciones Andino Amazónicas (FIAAM).

41. van Dijk, T. y Rodrigo Mendizábal, I. (1999). Análisis del discurso social y político. Quito: Ediciones ABYA-YALA y Escuela de Comunicación Social, Universidad Politécnica Salesiana. Recuperado de https://bit.ly/2tjVqCn

42. van Dijk, T. (1984). Prejudice in discourse. An analysis of ethnic prejudice in cognition and conversation. Ámsterdam: Benjamins. Recuperado de http://bit.ly/2FMwkzP

43. van Dijk, T. (2003). Ideología y discurso. Barcelona: Ariel.

44. van Dijk, T. (2005). Ideología y análisis del discurso. Utopía y Praxis Latinoamericana. Revista Internacional de Filosofia Iberoamericana y Teoría Social, 29, 9-36.

45. van Dijk, T. (2009). Discurso y poder. Barcelona: Gedisa Editorial.

46. van Dijk, T. (2010). Análisis del discurso del racismo. Crítica y Emancipación, 2 (3), 65-94.

47. Vigil, N. (2010). Racismo en el discurso sobre los asháninkas de Satipo. Discurso \& Sociedad, 4 (3), 538-578.

48. Wodak, R. y Meyer, M. (comp.). (2003). Métodos de análisis crítico de discurso. Barcelona: Gedisa Editorial.

49. Wodak, R. (2011). Politics as usual: investigating political discourse in action. En J. Gee y M. Handford (Eds.), The Routledge Handbook of Discourse Analysis. London: Routledge, 525-540. 